\title{
Effects of trunk Muscles Endurance, Hip Joint Muscular Strength, and Pelvic Alignment on Mild Low Back Pain
}

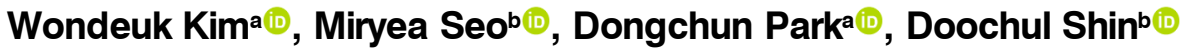 \\ ${ }^{a}$ Department of physical therapy, graduate school of Kyungnam University, Republic of Korea \\ ${ }^{b}$ Department of physical therapy, College of health sciences, Kyungnam University, Republic of Korea
}

Objective: Low back pain easily becomes chronic and has a high recurrence rate. Therefore, it is most important to prevent chronicity and reduce the risk of recurrence in the early stages of back pain or at the stage with mild pain. Therefore, this study was conducted to compare hip joint muscle strength, trunk muscle endurance, and pelvic alignment between subjects with mild low back pain and subjects without back pain.

Design: Crossed-sectional study

Methods: The study was conducted by recruiting 30 students in their twenties who are enrolled in K University in Gyeongsangnam-do, and classifying them into 15 patients with mild back pain and 15 patients with normal. The subjects who participated in the experiment were measured for hip flexor and extensor muscle strength, trunk flexion and extension muscle endurance, and pelvic alignment. To measure hip joint muscle strength, biodex was used, and muscle endurance of the trunk was recorded at the end range of the trunk flexion and extension. And pelvic alignment was measured using Formetric 4D.

Results: There were no significant differences in hip joint muscle strength, pelvic alignment, and trunk extension muscle endurance. The retention time was found to be significantly shorter in the mild low back pain group than in the normal group for trunk flexion muscle endurance.

Conclusions: In the early stages of back pain or in the mild pain stage, training to increase muscle endurance of the flexor muscles may be helpful.

Key Words: Low back pains, Muscle strength, Physical endurance

\section{서론}

비 특이적 허리통증이란 영상검사 등의 의학적 검사에 서 특별한 원인이 발견되지 않고 나타나는 허리통증을 말 한다[1].

허리통증의 90 95\%가 비특이적 허리통증으로 진단되 고 대부분의 사람들의 일생에 1 번이상은 경험하는 흔한 질환이다[2].

허리통증은 본질적으로 쉽게 재발하는 증상이다[3]. Bergquist 등[4]은 급성 허리통증 환자를 1년간 사후분석 한 결과 $65 \%$ 가 1 회 이상 추가적인 통증이 발현되었다고 보고 되었다.
이러한 비특이적 허리통증을 발생시키는 위험요인에는 나이, 성별, 근력, 유연성, 체격, 체중 등 다양한 요소들이 기여하는 것으로 보고되고 있다[5-7].

그 중에서도 몸통과 엉덩관절의 근력, 골반과 척추의 정렬은 다양한 연구에서 허리통증의 위험요소로 기여한다 고 보고되고 있다 $[7,8]$.

만성 허리통증이 있는 사람의 복부근육, 척추 주위근, 뭇갈래근의 근력이 허리통증이 없는 사람에 비하여 현저히 약하거나 심한 경우 근 위축이 발견되기도 한다 $[9,10]$.

엉덩관절 주변 근육의 근력은 활동하는 동안의 몸통의 자세조절에 기여하고 근력의 약화는 허리통증의 위험요소 로 작용할 수 있다[11].

Received: May 11, 2021 Revised: May 31, 2021 Accepted: Jun 2, 2021

Corresponding author: Doochul Shin(ORCID https://orcid.org/0000-0002-8873-9541)

Department of Physical Therapy, Kyungnam University

7 Kyungnamdaehak-ro, Masanhappo-gu, Changwon, Gyeongsangnam-do, 51767 Republic of Korea

Tel: + 82-55-249-2017 Fax: + 82-505-999-2173 E-mail: icandox77@kyungnam.ac.kr

This is an Open-Access article distributed under the terms of the Creative Commons Attribution Non-Commercial License (http://creativecommons.org/licenses/ by-nc/4.0) which permits unrestricted non-commercial use, distribution, and reproduction in any medium, provided the original work is properly cited.

Copyright @ 2021 Korean Academy of Physical Therapy Rehabilitation Science 
Nicholas 등[12]은 만성 허리통증이 있는 사람들이 허 리통증이 없는 사람들에 비하여 엉덩관절 주변 근육의 근 력이 약하고 특히 중간볼기근의 근력이 현저히 떨어지는 양상을 보인다고 하였다.

또한 골반의 기울기 변화는 척추의 비정상 정렬을 만드 는데 기여하게 되어 허리뼈에 더 큰 스트레스를 발생 시 킨다[13]. 골반의 경사도 증가 정도와 비대칭의 정도가 허 리통증과 연관되어 있다는 다양한 연구들이 보고되고 있 다 $[14,15]$.

Anita 등[16]은 허리통증이 있는 사람이 없는 사람에 비하여 골반의 전방경사가 더 높게 나타난다고 하였다. Felipe 등[17]의 연구에서 뒤넓다리근의 긴장이 증가된 허리통증 환자의 자세와 몸통 숙이기 동작 시 허리뼈와 골반의 움직임을 분석한 결과 골반의 후방경사가 발견되 고 몸통 숙이기 동작 시 전방경사 움직임이 제한 되었다 고 보고하였다.

이처럼 많은 임상연구에서 몸통과 엉덩관절의 근력, 골 반의 기울기의 정도가 영향을 준다고 보고되고 있다. 하 지만 몸통의 근지구력이 허리통증에 어떠한 영향을 주는 지에 대한 연구는 부족 하였다. 또한 골반의 좌우 비대칭 과 허리통증의 연관성에 있어서는 골반 비대칭이 허리통 증과 연관된다는 연구가 있는 반면 거의 영향을 주지 않 거나 약한 정도의 영향만 준다는 서로 상충된 결과를 보 이고 있다.

또한 허리통증은 재발률이 높은 특성을 가지기 때문에 통증이 나타난 초기단계 또는 경미한 통증을 가지고 있는 단계에서 만성화 또는 재발의 위험을 줄이는 것이 무엇보 다 중요하다.

따라서 본 연구에서는 경미한 허리통증을 가진 사람을 대상으로 몸통과 엉덩관절의 근력, 근지구력, 골반 기울기 정도, 골반 비대칭 정도가 허리통증에 어떠한 영향을 주 는지 알아보고자 한다.

\section{연구방법}

\section{대상자 선정}

본 연구는 경상남도 창원시에 위치한 $\mathrm{K}$ 대학 학생 중 한국형 오스웨스트리 허리통증 장애지수(KODI) 9점 이 하의 경미한 허리통증이 있는 15 명과 허리통증이 없는 15 명을 대상으로 실시되었다. 실험군의 제외기준은 한국형 오스웨스트리 허리통증 장애지수 9점을 초과 하는 자, 척 추 감염이나 골절이 있는 자, 허리뼈, 복부, 골반, 엉덩관 절의 수술병력이 있는 자, 하지 방사통 등 신경학적 증상 이 있는 자로 하였고 대조군은 허리통증과 관련한 어떠한 병력이나 증상도 없는 자로 선정하였다. 연구에 참여한
모든 대상자는 연구의 절차와 목적에 대해 충분히 설명을 듣고 동의서에 서명하였다.

\section{연구절차}

본 연구는 경미한 비특이적 허리통증을 가진 대상자와 허리통증이 없는 대상자 사이의 엉덩관절 근력, 몸통의 근지구력, 골반의 기울기의 차이를 비교하기 위해 실시되 었다.

연구에 참여한 30 명의 대상자들은 엉덩관절 근력을 측 정하기 위해 biodex(system4 pro, Biodex Inc., USA)를 이용하였고 몸통의 근지구력은 몸통 굽힘과 폄의 유지시 간을 측정하였다. 골반의 정렬을 측정하기 위해 Formetric4D (formetric 4D, DIERS biomedical solutions, Germany) 를 이용하였다.

\section{엉덩관절 근력}

엉덩관절 근력은 biodex(system4 pro,Biodex Inc., USA)를 이용하여 측정 하였다. 바로 누운 자세에서 넓다 리 전면 부위에 패드를 고정 시키고 회전축과 다이나모메 터(dynamoter)를 일치시켜 정확한 측정치가 도출 되도록 하였다.

엉덩관절 신전을 0 도 굽힘을 120 도까지, 각속도는 $60 \% \mathrm{sec}$ 에서 5 회로 설정하고 시작 신호와 함께 최대의 힘으로 굽 힘과 신전운동을 지시하였다.

\section{몸통 근지구력}

몸통의 근 지구력은 몸통 굽힘과 폄 동작의 유지시간을 기준으로 측정되었다.

각 동작의 유지시간을 기록하였고 몸통굽힘은 바로 누 운 자세에서 엉덩관절 45 도 무릎관절 90 도 굽히고 손을 목뒤에 위치시키고 몸통을 굽혀 날개뼈아래각이 침대에서 떨어지는 지점에서 유지하였다. 몸통 폄 지구력 측정을 위해 엉덩뼈 능선을 침대 끝에 위치시키고 골반과 무릎관 절에 스트랩을 묶어 고정한 자세를 취한다. 검사대에서 30 도 정도 몸통을 굽힌 상태에서 허리를 세워 몸통을 편 자세를 유지시켰다.

각 동작별 유지 시간에 따라 5 단계로 나누어 점수화 하였으며 각 점수별 기준 다음과 같다.

5점 : 20 30초 유지 가능, 4점 : 15 20초 유지가능, 3 점 : 1 10초 유지가능, 2점 : 손을 몸통과 나란히 하고 1 10초 유지가능 1점 : 운동없이 근 수축만 가능 


\section{골반정렬}

골반의 정렬을 측정하기 위해 Formetric $4 \mathrm{D}$ (formetric 4D, DIERS biomedical solutions, Germany)를 이용하였다. 연구 대상자들은 상의를 탈의하고 목부터 엉덩이 윗부 분까지 노출한 후 연구장비의 발판 위에 올라서서 촬영을 실시하여 골반의 정렬을 측정하였다.

6초간 촬영하여 측정되었으며 골반 기울임각(pelvic tilt), 골반뒤틀림각(pervic torsion)을 측정하였다.

골반기울임각은 골반의 양쪽 뒤앞엉덩뼈가시(PSIS)를 기준으로 좌/우 높이 차이 정도를 말하며 골반뒤틀림각은 골반의 양쪽 PSIS에서 직각선을 만들었을 때 양쪽 골반 의 비틀린 정도를 말한다. 오른쪽으로 비틀어진 값은 $(+)$ 로 표시하였고 왼쪽으로 비틀어진 값은 (-)로 표시하였다.

\section{통계분석}

본 연구의 통계적 분석은 SPSS(ver21.0, IBM Co., USA)를 사용하였다. 그룹간의 근력, 근지구력, 골반정렬 을 비교하기 위하여 Mann-Whitney의 U 검정을 사용하 였고 통계분석을 위한 유의수준은 0.05 이하로 하였다.

\section{연구결과}

본 연구에 총 30 명의 대상자가 참여하였고 경미한 허리 통증군 15 명, 정상군 15 명으로 구분되었다. 경미한 허리통 증군의 나이는 평균 $22.67 \pm 1.4$ 세, 신장은 $164.85 \pm 6.95$ $\mathrm{cm}$, 몸무게는 $62 \pm 11.85 \mathrm{~kg}$, 허리통증 장애지수는 $3.6 \pm 0.99$, 통증강도는 $2.3 \pm 1.78$ 이었다. 정상군의 나이는 평균 $22.07 \pm 1.28$ 세, 신장은 $164.63 \pm 4.77 \mathrm{~cm}$, 몸무게는 $62.75 \pm 10.33 \mathrm{~kg}$, 허리통증 장애지수는 0 , 통증강도는 0 인 것 으로 나타났다(Table 1).

경미한 허리통증군과 정상군 사이의 엉덩관절 근력 차 이는 hip flexion power, hip extension power 모두 유의 한 차이가 없었다(Table 3 ).

그룹간의 몸통 근지구력 차이는 몸통굽힘 지구력은 경 미한 허리통증군 $16.67 \pm 5.31$, 정상군 $23.06 \pm 4.37$ 초로 유 의한 차이가 있었고, 몸통 폄 근지구력은 그룹간에 유의 한 차이가 없었다(Table 2).

Table 1. The General characteristics of subjects $\quad(n=30)$

\begin{tabular}{lll}
\hline & Normal group & Low back pain group \\
\hline Age (years) & $22.07(1.28)$ & $22.67(1.4)$ \\
Weight $(\mathrm{kg})$ & $62.75(10.33)$ & $62.00(11.85)$ \\
Height $(\mathrm{cm})$ & $164.63(4.77)$ & $164.85(6.95)$ \\
ODI (score) & 0 & $3.6(0.99)$ \\
NPRS (score) & 0 & $2.3(1.78)$ \\
Male & $4 / 15$ & $5 / 15$ \\
Female & $11 / 15$ & $10 / 15$ \\
\hline
\end{tabular}

The values are presented mean (SD)

ODI: oswestry disability index, NPRS: numeric pain rating scale.

Table 2. Comparison of trunk muscles endurance retention time and grade

\begin{tabular}{llll}
\hline & Mild back pain & normal & p \\
\hline Trunk flexion retention time & $16.67(5.31)$ & $23.06(4.37)$ & 0.004 \\
Trunk extension retention time & $23.40(3.01)$ & $23.00(3.68)$ & 0.271 \\
Trunk flexion grade & $3.08(1.37)$ & $4.46(1.18)$ & 0.838 \\
Trunk extension grade & $5.00(0.00)$ & $4.87(0.51)$ & 0.775 \\
\hline
\end{tabular}

The values are presented mean (SD)

Table 3. Comparison of pelvic alignment and hip muscles power

\begin{tabular}{llll}
\hline & Mild back pain & normal & p \\
\hline Pelvic Lateral tilt & $3.64(3.02)$ & $3.47(3.81)$ & 0.806 \\
Pelvic a/p tilt & $21.27(9.13)$ & $16.87(8.65)$ & 0.081 \\
Hip flexion power & $29.47(11.85)$ & $29.77(10.45)$ & 0.512 \\
Hip extension power & $24.40(14.15)$ & $20.52(9.65)$ & 1.000 \\
\hline
\end{tabular}

The values are presented mean (SD)

Pelvic a/p tilt: pelvic anterior and posterior tilt 
그룹간의 골반정렬 차이를 비교한 결과 두 그룹간의 유 의한 차이가 없는 것으로 나타났다(Table 3).

\section{고찰}

본 연구는 경미한 허리통증이 있는 사람과 허리통증이 없는 사람 사이의 엉덩관절 근력, 몸통의 근지구력, 골반 정렬의 차이를 비교하기 위하여 실시되었다.

본 연구의 결과에서 엉덩관절 근력, 골반의 정렬, 몸통 폄 근지구력은 유의한 차이가 없었다. 이러한 결과는 연구 에 참여한 대상자들이 오스웨스트리 허리통증 장애지수 9 점 이하의 경미한 증상과 장애를 가진 사람들로 구성되었 기 때문에 엉덩관절 근력, 골반의 정렬, 몸통 폄근의 근지 구력의 유의미한 차이를 보이지 않았던 것으로 생각된다.

몸통 폄근의 근지구력은 허리통증군에서 5 점, 정상군에 서 4.87점으로 통계적으로 유의한 차이는 없었지만 오히 려 정상군에서 더 낮은 결과가 나타났다. 이러한 결과는 허리통증으로 인한 뭇갈래근의 약화로 인한 척추기립근의 과 활성화 $[9,10]$ 때문인 것으로 생각된다.

De souse 등[18]이 수행한 체계적 고찰에서 허리통증 이 있는 사람과 건강한 대조군간의 하지의 근력을 측정 비교한 결과 중간볼기근, 큰볼기근의 평균 근력이 허리통 증 환자군에서 유의하게 낮은 것으로 나타났다.

하지만 본 연구에서는 허리통증에 영향을 줄 수 있는 특정한 근육의 근력을 측정한 것이 아닌 엉덩관절굽힘근, 폄근 전체의 근력을 측정하였기 때문에 협력근들의 보상 작용을 충분히 제어하지 못하여 이러한 결과가 나온 것으 로 생각된다.

Robert A 등[19]이 수행한 체계적 고찰에서 허리통증 이 있는 대상자 들은 허리뼈 가동범위 감소, 움직임 속도 감소, 고유감각의 감소는 있었지만 허리뼈와 골반의 기울 기 각도는 차이가 없는 것으로 나타났다. 또한 Anita 등 [16]은 허리통증 환자의 골반 기울기는 연령이 증가함에 따라 경사각이 커진다고 하였다.

본 연구는 허리통증의 강도가 경미하고 20 대의 비교적 젊은 사람을 대상으로 실시하였기 때문에 골반정렬의 차 이가 없었던 것으로 생각된다.

본 연구에서 몸통 근육의 근지구력을 측정한 결과 경미 한 허리통증군이 정상군에 비해 몸통 굽힘근의 근지구력 에서 유의하게 낮은 것으로 나타났다.

Shabanam 등[20]이 수행한 체계적 고찰에서 허리통증 이 있는 대상자들은 복부 근육의 근활성도 감소, 근육 두 께 감소, 근력 및 근지구력의 감소가 관찰된다고 하여 본 연구와 비슷한 결과를 얻었다.

허리 통증은 근본적으로 만성화되기 쉽고 재발율이 높 은 특성을 가지고 있다 $[3,4]$. 따라서 만성화 및 재발 방
지를 위한 초기 단계에서의 관리가 아주 중요하다. 그러 한 점에서 본 연구의 결과는 허리통증의 초기단계에서 효 과적인 관리를 위한 방향을 제시하고 있다고 볼 수 있다.

하지만 본 연구의 대상자가 20 대 남녀로 실시되어 모 든 연령대에서 일반화 될 수 없고 허리통증에 영향을 줄 수 있는 엉덩관절의 가동성을 측정하지 않은 점, 그리고 엉덩관절 근력 측정에서 측면 안정성을 담당하는 외전근 의 근력을 측정하지 않은 점은 본 연구의 제한점이라고 할 수 있다.

향후의 연구에서는 허리통증에 영향을 줄 수 있는 더 다양한 요소들을 고려하여 연구가 진행되어야 할 것으로 생각된다.

경미한 허리통증이 있는 대상자들은 몸통 굽힘 근육의 지구력이 약한 것으로 나타났다. 이러한 결과는 허리통증 의 초기 단계에서 몸통 굽힘 근육의 지구력 회복이 재발 및 만성화 방지를 위해 필수적인 요소가 될 수 있다는 것 을 의미한다고 볼 수 있다.

\section{참고문헌}

1. Maher C, Underwood M, Buchbinder R. Non-specific low back pain. Lancet. 2017;389:736-47.

2. Bardin LD, King $P$, Maher CG. Diagnostic triage for low back pain: a practical approach for primary care. Med J Aust. 2017;206:268-73.

3. Von Korff M, Barlow W, Cherkin D, Deyo RA. Effects of practice style in managing back pain. Ann Intern Med. 1994;121:187-95.

4. Bergquist-Ullman M, Larsson U. Acute low back pain in industry: a controlled prospective study with special reference to therapy and confounding factors. Acta Orthopaedica. 1977;48:1-117.

5. Delitto A, George SZ, Van Dillen L, Whitman JM, Sowa G, Shekelle P, et al. Low back pain. J Orthop Sports Phys Ther. 2012;42:A1-57.

6. Furtado RN, Ribeiro LH, Abdo Bde A, Descio FJ, Martucci CE, Jr., Serruya DC. Nonspecific low back pain in young adults: associated risk factors. Rev Bras Reumatol. 2014;54:371-7.

7. Parreira P, Maher CG, Steffens D, Hancock MJ, Ferreira ML. Risk factors for low back pain and sciatica: an umbrella review. Spine J. 2018;18: 1715-21.

8. Delitto A, George SZ, Van Dillen L, Whitman JM, Sowa G, Shekelle P, et al. Low back pain. J Orthop Sports Phys Ther. 2012;42:A1-57. 
9. Goubert D, Oosterwijck JV, Meeus M, Danneels L. Structural Changes of Lumbar Muscles in Non-specific Low Back Pain: A Systematic Review. Pain physician. 2016;19:E985-E1000.

10. Kato S, Murakami H, Demura S, Yoshioka K, Shinmura K, Yokogawa N, et al. Abdominal trunk muscle weakness and its association with chronic low back pain and risk of falling in older women. BMC Musculoskelet Disord. 2019;20:273.

11. Alsufiany MB, Lohman EB, Daher NS, Gang GR, Shallan AI, Jaber HM. Non-specific chronic low back pain and physical activity: A comparison of postural control and hip muscle isometric strength: A cross-sectional study. Medicine (Baltimore). 2020;99:e18544.

12. Cooper NA, Scavo KM, Strickland KJ, Tipayamongkol N, Nicholson JD, Bewyer DC, et al. Prevalence of gluteus medius weakness in people with chronic low back pain compared to healthy controls. Eur Spine J. 2016;25:1258-65.

13. Al-Eisa E, Egan D, Deluzio K, Wassersug R. Effects of pelvic asymmetry and low back pain on trunk kinematics during sitting: a comparison with standing. Spine. 2006;31:E135-43.

14. Falk Brekke A, Overgaard S, Hróbjartsson A, Holsgaard-Larsen A. Non-surgical interventions for excessive anterior pelvic tilt in symptomatic and non-symptomatic adults: a systematic review. EFORT Open Rev. 2020;5:37-45.

15. Pierannunzii L. Pelvic posture and kinematics in femoroacetabular impingement: a systematic review. J Orthop Traumatol. 2017;18:187-96.

16. Król A, Polak M, Szczygieł E, Wójcik P, Gleb K. Relationship between mechanical factors and pelvic tilt in adults with and without low back pain. $J$ Back Musculoskelet Rehabil. 2017;30:699-705.

17. Jandre Reis FJ, Macedo AR. Influence of Hamstring Tightness in Pelvic, Lumbar and Trunk Range of Motion in Low Back Pain and Asymptomatic Volunteers during Forward Bending. Asian Spine J. 2015;9:535-40.

18. de Sousa CS, de Jesus FLA, Machado MB, Ferreira G, Ayres IGT, de Aquino LM, et al. Lower limb muscle strength in patients with low back pain: a systematic review and meta-analysis. J Musculoskelet Neuronal Interact. 2019;19:69-78.
19. Laird RA, Gilbert J, Kent P, Keating JL. Comparing lumbo-pelvic kinematics in people with and without back pain: a systematic review and meta-analysis. BMC Musculoskelet Disord. 2014;15:229.

20. ShahAli S, Shanbehzadeh S, Ebrahimi Takamjani I. Application of Ultrasonography in the Assessment of Abdominal and Lumbar Trunk Muscle Activity in Participants With and Without Low Back Pain: A Systematic Review. J Manipulative Physiol Ther. 2019;42:541-50. 